\title{
The Point of Interpreting Arguments
}

\author{
JONATHAN BERG University of Haifa
}

Key Words: Argument, interpretation, intentions.

\begin{abstract}
It is wrong to think that questions of interpretation are significant in informal logic only to the extent that they contribute to the assessment of an argument's conclusion. For one thing, logic is essentially about validity, about that in virtue of which conclusions do or do not follow from given premises, and not about the truth or falsity of conclusions by themselves. Secondly, the evaluation of a given argument requires first determining what the given argument is. Moreover, since arguments are given in rational discourse in order to persuade in order to arrive, by reason, at agreement-it is necessary to address the very arguments that arguers actually intend.
\end{abstract}

Any piece of argumentative prose gives rise to the following questions:

(i) What is (are) the given argument(s)?

(ii) What good or interesting arguments does the text bring to mind?

(iii) What good or interesting arguments can be given for or against the given conclusion?

(iv) Is the conclusion true?

Which are the questions to consider when interpreting arguments for logical analysis, and which questions should be addressed in the informal logic curriculum?

It is tempting to think that since the point of an argument is to convince the audience of its conclusion, the primary question about any piece of argumentative prose is whether the conclusion is true, and questions of interpretation are significant only to the extent that they contribute to the assessment of the conclusion. ${ }^{2}$ On this view the questions above are listed in reverse order of importance-it matters not what argument the author was advancing, but only what arguments can be gleaned from the text to help settle the question about the conclusion. Indeed, for readers clever enough to arrive on their own at whatever arguments the text has or suggests, the text would be of no use, and so there would be no point in considering it at all. And on the most radical version of this view, arguments may be insignificant altogether, given some way of determining the truth or falsity of their conclusions without them. ${ }^{3}$ The related pedagogical position is that the informal logic curriculum should be concerned not with how to extricate the authors' arguments from argumentative texts, but with how to make use of such texts in reasoning about the authors' conclusions.

Having presented an approach to the interpretation of argumentative prose, treating it as essentially a matter of arriving at the argument given by the arguer, I would like to explain in this paper why we should resist the temptation to minimize the importance to informal logic of questions of interpretation. ${ }^{4}$

\section{Logic, Validity, and Truth}

First of all, focusing on conclusions, rather than on the arguments given for them, is to engage in an enterprise that must be distinguished from logic. ${ }^{5}$ For logic is essentially about validity, about 
that in virtue of which conclusions do or do not follow from given premises, and not about the truth or falsity of conclusions by themselves. ${ }^{6}$ That is, the fundamental logical question about any argument is not whether the conclusion is true, but whether it follows from the premises. So any approach to arguments where the main objective is to determine the truth or falsity of particular conclusions is simply beyond the domain of logic.

Basically the same is to be said with regard to reasonableness or acceptability, as opposed to truth. Although logic can plausibly be construed as concerning the reasonableness or acceptability of a conclusion relative to certain premises ${ }^{7}$, logic clearly does not concern the reasonableness or acceptability of a conclusion in and of itself. Of course, the reasonableness of a proposition depends on there being good reasons for it, that is, on there being good arguments for it, and so assessments of reasonableness do require logical considerations. But the abundance of valid arguments for unreasonable conclusions shows that reasonableness involves much more than just logic.

It should be clear that nothing I say here is intended to detract from the general importance of questions of truth (or reasonableness or acceptability). Indeed, for ordinary everyday purposes questions of truth are the ones that count, and questions of validity are only of derivative importance, but the question at hand is not about what matters in general, but about what matters in informal logic. ${ }^{8}$

Nor would I deny the obvious pedagogical value of curricula that develop the ability to address questions of truth (or reasonableness or acceptability) - an ability which is obviously of paramount importance in getting about in the world. But the point is that this is not therefore part of the informal logic curriculum.

It is even questionable whether an enterprise so general as the determination of the truth or falsity (or reasonableness, etc.) of given conclusions (propositions) -in effect, the very pursuit of truth-can be classified as part of any particular field of study (or curriculum) at all. The problem is not that no field involves determining the truth or falsity of given propositions, but that every field does. The conclusion of an argument can be a proposition belonging to any area of study, from ethics to engineering, and so the inquiries into the truth of such propositions amount to nothing less than the inquiries of all areas of study. Logic, on the other hand, dealing with relations between propositions, as opposed to (nonlogical) propositions themselves, thereby maintains a kind of subject neutrality, allowing for the study and teaching of logic as a field in itself, not inextricably subsumed under every other field of study. ${ }^{9}$

\section{Giving Arguments and Given Arguments}

Conceding that informal logic concerns arguments and their validity (or invalidity), rather than the conclusions of arguments and their truth (or falsity), one may nevertheless fail to recognize just how significant questions of interpretation are in informal logic, for one may fail to recognize the crucial role of interpretation in the treatment of arguments. Granting the importance of arguments while still clinging to the conclusion oriented approach, one may think that the arguments to be dealt with are none other than those one constructs for or against a particular conclusion. With regard to arguments of one's own construction -whether constructed with or without the help of a text-questions of interpretation seem not to arise. And if the whole role of the text is only to facilitate one's own construction of arguments, then the intentions of the text's author would not really matter; the arguments to be addressed would be one's own (re)constructions, and it would be irrelevant whether any of them were indeed the author's argument. 
The problem with this view of informal logic is best seen in the light of the distinction between the production of one's own arguments and the evaluation of the arguments of others-between giving arguments and assessing given arguments. Retaining the emphasis on the conclusions of arguments as the focus of investigation, the view in question depicts an enterprise of giving arguments, as opposed to one of dealing with given arguments. Though arguments thus remain at the fore in this picture, they are only arguments one formulates oneself (even if inspired by the words of another); and although arguments may get evaluated according to this picture, they are only arguments given by oneself and not arguments given by others.

Of course, marshalling arguments for and against a particular proposition is often a good thing to do, and it is certainly a good thing for students to learn how to do. But it would be wrong to mistake this noble pursuit for informal logic. For at least one major concern in informal logic, both in research and in teaching, is the evaluation of arguments given by others. It should be clear, though, that one cannot begin to evaluate a given argument without first determining what the given argument is. That is, dealing with given arguments, as opposed to giving one's own arguments, requires addressing the basic question of argument interpretation, viz., "What is the argument given?" So informal logic fundamentally involves argument interpretation. ${ }^{10}$

\section{The Discourse of Reason}

One may yet object to this conception of informal logic as concerned with arguments given by others rather than just arguments of one's own construction. Since it is an obvious empirical fact that the treatment of arguments given by others is surely a large part of what is currently classified as informal logic, I take it that the question raised here is not descriptive but prescriptive-why should informal logic be directed towards the arguments given by others rather than just concern itself with arguments one constructs oneself (even if in the light of the words of others)?

For one thing, there is the pedagogical point that because of the special perspective from which one's own arguments are viewed, a student's logical skills will not be developed as well if they are applied only to the student's own arguments. For it is only natural to overlook in arguments of one's own devising what one might notice more readily in the arguments of others. Even if the argument one formulates and considers is not an argument one endorses, as would often be the case with arguments inspired by a given text, one is less likely to see in such an argument anything which diverges from one's own expectations. And even though it is clearly important to learn how to assess "objectively" arguments of one's own invention, especially if one endorses them, it remains nevertheless questionable how well one's logical skills can be developed as long as they are not subjected to any arguments transcending one's own expectations.

But more important than these pedagogical considerations are dialectical considerations about the role of argument in the discourse of reason. Arguments are given in rational discourse in order to persuade, in order to arrive, by reason, at agreement. It is wrong, therefore, to assume that the only point, or even just the main point, of considering an argument is to settle-for oneself - the issue in question. Rather, arguments in the discourse of reason are examined with the aim of coming to an agreement about their proper disposition. Thus, it is necessary to address the very arguments that others actually intend. For turning one's attention to any other argument would not typically help to resolve the question about the argument actually given. This is especially significant in the case of critical remarks, since 
one is not likely to be convinced of faults in one's own argument by criticism of a different argument. Arguments in the discourse of reason are thus like remarks in a conversation: to reply to anything other than what was intended is simply to miss the point, and so it is crucial to determine and to address what was actually intended. ${ }^{11}$

\section{Notes}

1 Remaining neutral with regard to meta-ethical questions and theories of truth, I use the word 'true' in the loose ordinary way, appropriate for normative conclusions.

2 See, for instance, Peter Davson-Galle's "Interpreting Arguments and Judging Issues," Informal Logic, 11 (1989), 41-5.

3 Hence, Davson-Galle's admission that "in a sense, what I propose is not aptly thought of as argument analysis at all" (p. 45, n. 2).

4 "Interpreting Arguments," Informal Logic, 9 (1987), 13-21.

5 Of course, I mean here and elsewhere in the discussion not to be speaking of logical conclusions, such as the conclusion of one argument with respect to a second argument that the conclusion of that second argument follows from its premises.

6 I deliberately do not restrict my talk of validity to deductive validity. I think the relevant notion of validity is ultimately a matter of rationality, as I argue in "Validity and Rationality," in Argumentation Hluminated, ed. F. van Eemeren, et al., Amsterdam: Sicsat, 1992, pp. 104-12.

7 Especially informal logic, as I have suggested, op, cit.

8 Since the strength of an argument obviously depends (in part) on the strength of its premises, the evaluation of arguments ultimately leads to questions of truth (or reasonableness or acceptability), with regard to particular premises. But the truth (etc.) of a premise is no more a matter of logic than the truth (etc.) of a conclusion (for all the same reasons). Perhaps this serves to distinguish "informal logic" from "critical thinking" and "argument analysis."

9 According to a popular opposing view, generally associated with Stephen Toulmin and his followers, logical inquiries, too, cannot be divorced from the inquiries of particular fields of study, on the grounds that the forms and norms of reasoning vary too much across fields to allow for any truly general principles of logic. But as much diversity as there may be, and as worthy as it may be of special attention, the negative conclusion about general principles of logic remains unwarranted. Indeed, the evidence in favour of a nonparticularized, field-independent logic seems to me much stronger than the evidence against it.

10 My position is obviously incompatible with theories of textual analysis that are not concerned with authors' intentions. One could treat the words of a text (argumentative or otherwise) as clouds in the sky, seeing in them whatever one will. But such an enterprise, regardless of whatever artistic value it may have, should not be confused with rational discourse.

11 I wish to thank James B. Freeman for comments on an earlier draft.

\section{JONATHAN BERG \\ DEPARTMENT OF PHILOSOPHY \\ UNIVERSITY OF HAIFA \\ HAIFA 31-905 ISRAEL}

